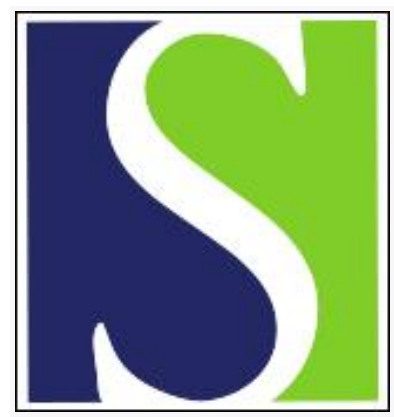

Scand J Work Environ Health 2014;40(2):176-185

https://doi.org/10.5271/sjweh.3401

Published online: 15 Nov 2013, Issue date: 01 Mar 2014

A multi-wave study of organizational justice at work and long-term sickness absence among employees with depressive symptoms

by Hjarsbech PU, Christensen KB, Bjorner JB, Madsen IEH, Thorsen SV, Carneiro IG, Christensen U, Rugulies R

Sickness absence due to mental ill-health increases, stressing the importance of focusing on the many employees at work with mental health issues. In this study, organizational justice had a protective effect on the risk of long-term sickness absence among men, but not women, with depressive symptoms. A protective effect of favorable changes in organizational justice was not found.

Affiliation: National Research Centre for the Working Environment, Lersø Parkallé 105, DK-2100 Copenhagen, Denmark. pmi@nrcwe.dk

Refers to the following text of the Journal: 2003;29(1):1-4

The following articles refer to this text: 2016;42(4):320-328;

2021;47(2):136-144

Key terms: depression; depressive symptom; long-term sickness absence; mental health; organizational justice; psychosocial work environment; repeated measurement; work ability

This article in PubMed: www.ncbi.nlm.nih.gov/pubmed/24241340

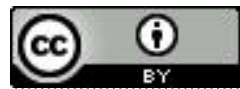




\title{
A multi-wave study of organizational justice at work and long-term sickness absence among employees with depressive symptoms
}

\author{
by Pernille U Hjarsbech, PhD, ${ }^{1}$ Karl Bang Christensen, PhD, ${ }^{2}$ Jakob B Bjorner, PhD, 1, 3 Ida E H Madsen, \\ PhD, ${ }^{1}$ Sannie V Thorsen, PhD, Isabella G Carneiro, PhD, ${ }^{1}$ Ulla Christensen, PhD, ${ }^{3}$ Reiner Rugulies, PhD ${ }^{1,3,4}$
}

\begin{abstract}
Hjarsbech PU, Christensen KB, Bjorner JB, Madsen IEH. Thorsen SV, Carneiro IG, Christensen U, Rugulies R. A multi-wave study of organizational justice at work and long-term sickness absence among employees with depressive symptoms. Scand J Work Environ Health. 2014;40(2):176-185. doi:10.5271/sjweh.3401
\end{abstract}

\begin{abstract}
Objectives Mental health problems are strong predictors of long-term sickness absence (LTSA). In this study, we investigated whether organizational justice at work - fairness in resolving conflicts and distributing work prevents risk of LTSA among employees with depressive symptoms.

Methods In a longitudinal study with five waves of data collection, we examined a cohort of 1034 employees with depressive symptoms. Depressive symptoms and organizational justice were assessed by self-administered questionnaires and information on LTSA was derived from a national register. Using Poisson regression analyses, we calculated rate ratios (RR) for the prospective association of organizational justice and change in organizational justice with time to onset of LTSA. All analyses were sex stratified.
\end{abstract}

Results Among men, intermediate levels of organizational justice were statistically significantly associated with a decreased risk of subsequent LTSA after adjustment for covariates [RR $0.49,95 \%$ confidence interval (95\% CI) $0.26-0.91]$. There was also a decreased risk for men with high levels of organizational justice although these estimates did not reach statistical significance after adjustment (RR 0.47, 95\% CI 0.20-1.10). We found no such results for women. In both sexes, neither favorable nor adverse changes in organizational justice were statistically significantly associated with the risk of LTSA.

Conclusions This study shows that organizational justice may have a protective effect on the risk of LTSA among men with depressive symptoms. A protective effect of favorable changes in organizational justice was not found.

Key terms depression; mental health; psychosocial work environment; repeated measurement; work ability.

Long-term sickness absence (LTSA) involves great individual and societal costs (1-3). Major depression $(4,5)$ but also less severe mental health problems, such as depressive symptoms (6-9), are strongly related to risk of LTSA. Thus, employees with mental health problems are at increased risk of LTSA and subsequent permanent exclusion from the labor market $(10,11)$. This is a growing public health concern as disability benefit claims and sickness absence due to mental health problems have increased in OECD countries (10). A newly published OECD report on mental health and labor market participation in Denmark concluded there is a need to address the large number of employees with mental health problems who are able to work but often struggling in their jobs (12).

In accordance with the International Classification of Functioning, Disability and Health of the World Health Organization (13), we regard the etiology of sickness absence as multifactorial (14) and characterized by a complex interplay between health conditions and contextual factors (13), including psychosocial working conditions. As working conditions are modifiable, identifying protective working conditions would be an important step in creating work environments that contribute to lower sickness absence rates and prevent labor market exclusion among employees with mental health problems.

\footnotetext{
1 National Research Centre for the Working Environment, Copenhagen, Denmark.

2 Department of Public Health, Section of Biostatistics, University of Copenhagen, Copenhagen, Denmark.

3 Department of Public Health, Section of Social Medicine, University of Copenhagen, Copenhagen, Denmark.

4 Department of Psychology, University of Copenhagen, Copenhagen, Denmark.
} 
In recent years, organizational justice has been increasingly discussed as a psychosocial working condition that might protect employees' health $(15,16)$. Organizational justice refers to equity in decision-making procedures and the extent to which employees are fairly treated at their workplace $(15,16)$. A recent review of 11 prospective studies showed that high organizational justice predicts a lower risk of poor mental health. Moreover, 4 of the studies reported an association of high organizational justice with decreased risk of sickness absence (17-20). The review concluded there is a need for further studies that examine whether changes in organizational justice may affect health (16).

To the best of our knowledge, no study has yet investigated whether organizational justice has beneficial effects on LTSA among employees with mental health problems. In this study, we examine whether organizational justice prevents risk of LTSA among employees with depressive symptoms. We applied a longitudinal design, measuring organizational justice and depressive symptoms during five waves of data collection while events of LTSA were continuously recorded in a national register. We hypothesized that high levels of organizational justice, and improvement in organizational justice from one wave to the next, decrease the risk of LTSA in a population at high risk of LTSA.

\section{Methods}

\section{Study design and population}

Psychosocial Work Environment and Workability among Employees with Depressive Symptoms (PEWED) is a follow-up study of participants recruited from a survey of the Danish population: the Danish National Working Environment Study (DANES).

During September-December 2008, 12584 Danish residents responded to the DANES survey (response rate $69 \%)(21,22)$. We invited these respondents to participate in PEWED if they (i) were between 18-65 years, (ii) were employed, (iii) responded by mailed or internet questionnaire, but not by telephone interview, as mode of administration can affect the answers (23), and (iv) had depressive symptoms, defined as a score of $\geq 10$ points on the Major Depression Inventory (MDI) (24, 25). Figure 1 gives an overview of the DANES and PEWED surveys. Of the 12584 DANES respondents (T0: baseline), 2271 fulfilled the inclusion criteria for PEWED and received a questionnaire measuring organizational justice and depressive symptoms in May 2009 (T1: first follow-up). Of those, $1478(65 \%)$ responded at $\mathrm{T} 1$ and constituted the PEWED study population.

The 793 non-responders were more likely to be men
( $49 \%$ versus $42 \%, \mathrm{P}=0.0014$ ) and younger ( 43.6 versus 46.5 years, $\mathrm{P}<0.0001)$. Non-responders and responders did not differ in mean baseline MDI score (17.3 versus 17.0, $\mathrm{P}=0.32$ ), organizational justice score (5.1 versus $5.1, \mathrm{P}=0.45$ ), or onset of LTSA ( $>3$ weeks) during follow-up $(14.6 \%$ versus $16.9 \%, \mathrm{P}=0.17)$.

The $1478 \mathrm{~T} 1$ responders received follow-up questionnaires in September 2009 (T2), January 2010 (T3), and May 2010 (T4). Participants were withdrawn from the study on request but not as a result of non-response. Of the 1478 T1-responders, there were 1344 (91\%), $1303(88 \%)$, and $1277(86 \%)$ responders at $\mathrm{T} 2, \mathrm{~T} 3$, and $\mathrm{T} 4$, respectively.

We excluded participants who had stopped working $(\mathrm{N}=191)$ or changed job $(\mathrm{N}=103)$ between $\mathrm{T} 0$ and $\mathrm{T} 1$. After list-wise deletion of participants with missing values on key variables $(\mathrm{N}=150)$, the final study sample comprised 1034 participants.

\section{Measures}

Measurement of organizational justice. Organizational justice was measured with two items from the justice scale of the Copenhagen Psychosocial Questionnaire version II (26). After the introductory sentence "These questions are not about your own work but about the whole organization where you are employed", participants were asked: "Are conflicts resolved in a fair way?" and "Is work distributed in a fair way?" Each item had five response categories: 0 (to a very low degree), 2.5 (to a low degree), 5.0 (partly), 7.5 (to a high degree), and 10 (to a very high degree). The Cronbach's alpha of the scale was 0.73 .

Responses were summed and the sum transformed to a scale ranging from $0-10$, with higher scores indicating higher levels of organizational justice. We calculated the average organizational justice score from the measurements of two successive waves (ie, the average of T0 and $\mathrm{T} 1 ; \mathrm{T} 1$ and $\mathrm{T} 2 ; \mathrm{T} 2$ and $\mathrm{T} 3$; and $\mathrm{T} 3$ and $\mathrm{T} 4)$. The average scores were then divided into groups of high $(>5$ points), intermediate ( $>3.75-5$ points) and low $(\leq 3.75)$ levels of organizational justice based on tertile split. Furthermore, we divided the organizational justice score from each single wave into groups of high, intermediate, and low levels of organizational justice based on tertile split. Then, we calculated the change in the level of organizational justice, as the change from one group to another at the subsequent wave (ie, the change from $\mathrm{T} 0$ to $\mathrm{T} 1 ; \mathrm{T} 1$ to T2; T2 to T3; and from T3 to T4). The changes were categorized depending on their direction as favorable (eg, from low to intermediate), adverse (eg, from high to intermediate), and as "no change".

Measurement of long-term sickness absence. We defined incident LTSA as $>3$ consecutive weeks of sickness absence during follow-up. We had four periods of approx- 


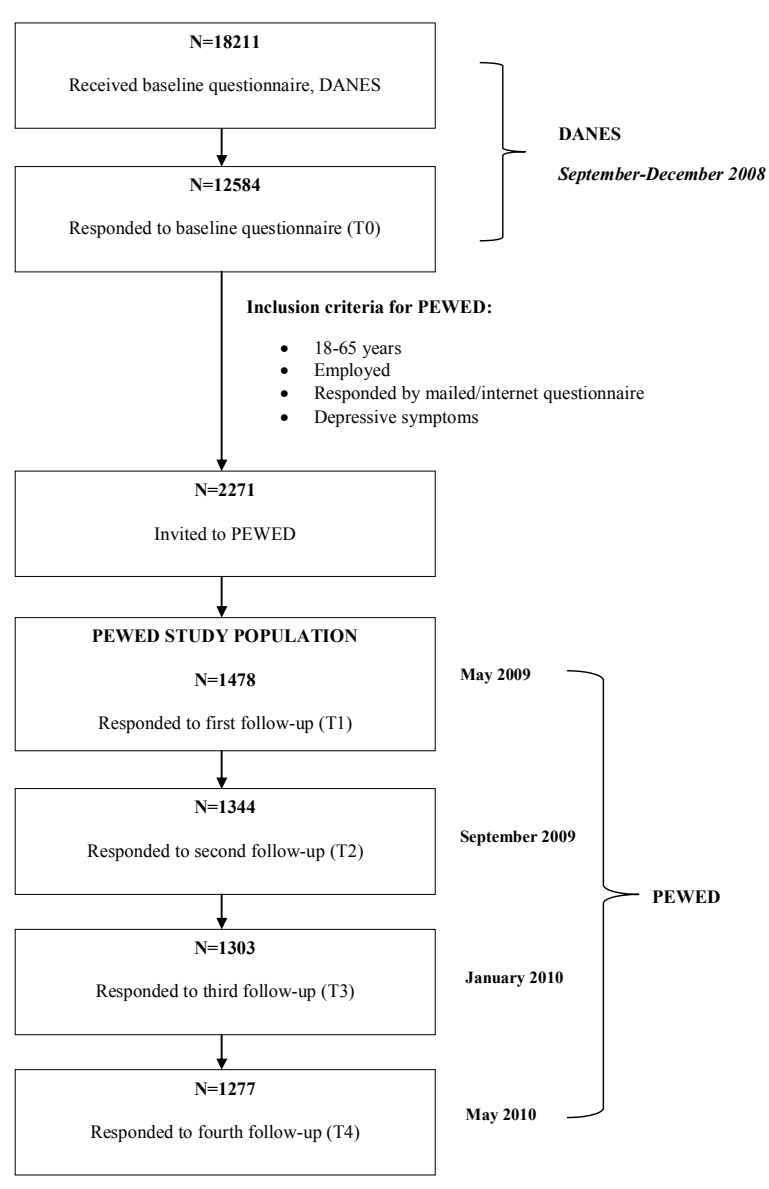

Figure 1. Flow chart of DANES and PEWED surveys.

imately four months of follow-up from T1-T2, T2T3, T3-T4 and T4-T4+four months, respectively. We retrieved data on LTSA by linking the unique social security number of each participant with the Danish Register for Evaluation of Marginalization (DREAM). DREAM contains all social transfer payments in Denmark for each week, including sickness absence benefits (27).

Measurement of depressive symptoms. We measured depressive symptoms with the MDI $(24,25)$, a rating scale of 10 items assessing the presence of depressive symptoms (24). The response categories measure symptom frequency during the last two weeks as: 0 (at no time), 1 (some of the time), 2 (slightly less than half the time), 3 (slightly more than half the time), 4 (most of the time), and 5 (all of the time). Responses are summed, yielding a scale from $0-50$, with higher scores indicating more severe depressive symptoms. We defined prevalence of depressive symptoms as an MDI score of $\geq 10$. We chose this cut-off point because earlier Danish cohort studies showed that participants scoring from 9-10 points had a statistically significant increased risk of LTSA $(9,28)$. The MDI score was assessed at T0 and in all follow-up surveys. The MDI score at T0 was used to define the study population while scores from $\mathrm{T} 0-\mathrm{T} 3$ were used as time-varying covariates in the analyses.

Measurement of covariates. We measured age (continuous variable), social class [categorized into (i) the salariat, (ii) intermediate occupations, and (iii) working class, in accordance with the three class model of the European Socioeconomic Classification (29)], cohabitation with partner or spouse (yes versus no), having children living at home (yes versus no), body mass index (BMI) [normal versus non-normal weight (underweight, overweight, obese)], smoking habits (never smoked versus current or previous smoker), units of weekly alcohol consumption, hours of weekly physical activity, pre-existing physician-diagnosed mental health problem (yes versus no), number of pre-existing physician-diagnosed diseases (hay fever/allergy, asthma, diabetes, cardiovascular disease, back disease, reduced hearing, skin disease, other diseases). See table 1 for a detailed description of these covariates. We selected these covariates because they have been associated with sickness absence (30-33). All information on covariates came from the baseline questionnaire (T0) except age, which was obtained from registers. The covariates were only assessed at baseline and not during follow-up and were therefore treated as time-invariant covariates.

In addition to the time-invariant covariates, we measured the continuous MDI score, psychological treatment (both non-medicinal and psychopharmacological), and stressful life events as time-varying covariates during follow-up (T1-T4). Stressful life events included (i) severe illness, accident or death of close family member, (ii) own severe illness or accident, and (iii) serious problems in relationship, divorce, or end of permanent relationship. Both psychological treatment and stressful life events were used as binary variables (yes, $\geq 1$ versus no) and selected because of their associations with mental health problems and sickness absence $(33,34)$.

\section{Statistical analysis}

Using Chi-squared and two sample t-tests we examined differences between PEWED and employed DANES participants without depressive symptoms (MDI score $<10$ ).

We calculated time at risk of LTSA as the time until onset of LTSA or time of censoring. Participants were censored if they were no longer at risk of LTSA (eg, if they were unemployed, retired, had emigrated or died indicated by entries in the DREAM registry), when they changed their job (based on reported date of job change in the questionnaires), or at the end of follow-up, whichever came first. Follow-up time was from T1-T2, T2-T3, T3-T4, and T4-T4+four months, respectively. 
Using Poisson regression analyses, we calculated rate ratios (RR) and 95\% confidence intervals (95\% CI) for the prospective association of level of organizational justice and change in organizational justice with time to onset of LTSA. The analyses included exposure to organizational justice in the four intervals between the five waves of data collection, ie, T0-T1, T1-T2, T2-T3 and T3-T4. For each of these four intervals, the prospective association between the exposure and onset of LTSA in the subsequent follow-up period was studied. For example, for the exposure period T0-T1, we examined the risk of LTSA in the four months after $\mathrm{T} 1$, ie, the time period T1-T2. This design is depicted in figure 2. We combined information from the four intervals in an overall analysis and used the logarithm to time at risk as an offset variable. The assumption of independence between observations is violated when using repeated measurements as measurements from the same individual are correlated. Therefore, we used Generalized Estimating Equations (GEE) to account for the dependence between the repeated observations within each participant. Analyses were conducted in PROC GENMOD, SAS 9.2 (SAS Institute, Cary, NC, USA).

Previous research on psychosocial working conditions and LTSA showed sex-specific effects $(35,36)$. Therefore, we tested if associations between organizational justice and LTSA were sex-specific. The test of interaction was statistically significant $(\mathrm{P}=0.02)$ and consequently sex-stratified analyses were performed. There was no interaction between organizational justice and depressive symptoms $(\mathrm{P}=0.98)$.

Except for age and social class, covariates were only included in the analyses if they were associated with LTSA $(\mathrm{P}<0.05)$ in separate Poisson regression analyses. Accordingly, we included: age, social class, BMI, smoking habits, pre-existing physician-diagnosed mental health problem, pre-existing physician-diagnosed diseases, psychological treatment, stressful life events (model I) and MDI score (model II). The analyses of changes in organizational justice were further adjusted for the initial level of organizational justice (eg, change

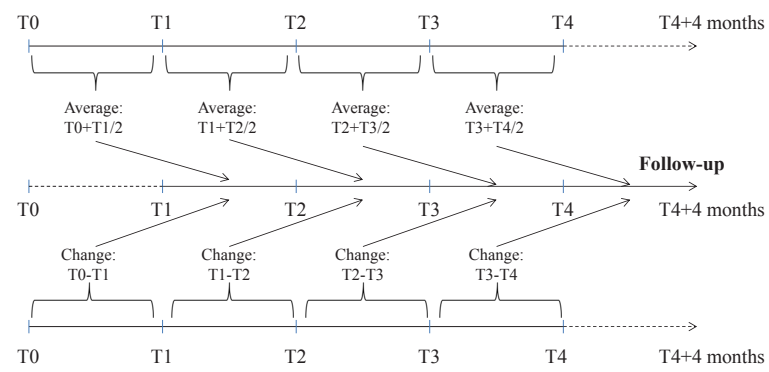

Figure 2. Design of analysis. between T0-T1 was adjusted for level of organizational justice at T0) (model III).

\section{Sensitivity analysis}

We conducted three sensitivity analyses. First, we repeated the analyses excluding participants with LTSA one year before baseline (T0). Second, we restricted the analyses to first occurrence of LTSA only. Third, we included weekly working hours as a covariate to examine if differences between men and women in the association of organizational justice and LTSA might be explained by differences in working hours.

\section{Results}

\section{Characteristics of the study population}

Table 1 compares characteristics of PEWED with DANES participants without depressive symptoms. Men and women from PEWED were more often diagnosed with a mental health problem by a physician, had more diseases, were more likely to be current or previous smokers, and had lower mean organizational justice scores than DANES participants. Men from PEWED consumed more alcohol than men from DANES, a difference that approached statistical significance. Women from PEWED were less likely to be (i) cohabiting, (ii) of normal weight, and (iii) physically active than DANES women. There were no statistically significant differences between the two samples regarding age, social class, and parental status.

At T0, all PEWED participants had an MDI score $\geq 10$ as this was the inclusion criterion for the study. During follow-up, the proportion of PEWED participants with an MDI score $\geq 10$ was $54.7 \%$ (T1), $53.1 \%$ (T2), $51.2 \%(\mathrm{~T} 3)$, and $50.8 \%$ (T4), respectively.

\section{Organizational justice and long-term sickness absence}

The 438 men and 596 women in PEWED yielded 1440 and 2007 observations, respectively. Of the $438 \mathrm{men}$, 47 men experienced $\geq 1$ LTSA event. A total of 82 events were observed, 23 men experienced 1 event and 24 experienced $\geq 1$ event. Of the 596 women, 109 experienced $\geq 1$ LTSA event. A total of 201 events were observed, 49 women experienced 1 event and 60 women experienced $\geq 1$ event. The mean time at risk was 66.7 weeks for men and 66.4 for women.

Table 2 shows the prospective association of levels of organizational justice with risk of LTSA stratified by sex. Compared to men with low levels of organizational justice, men with intermediate and high level of orga- 
Table 1. Characteristics of the Psychosocial Work Environment and Workability among Employees with Depressive Symptoms (PEWED) study population included in analyses $(\mathrm{N}=1034)$ and participants from the general population in the Danish National Working Environment Study (DANES) without depressive symptoms ( $\mathrm{N}=6463)$. [SD=standard deviation; BMI=body mass index; $\mathrm{MDI}=$ major depression inventory.]

Men
Women
Men

Sociodemographic factors

Age in years

Social class

The salariat

Intermediate occupations

Working class

Cohabiting

Having children living at home

Health-related behavior

BMI (normal weight)

Smoking habits (never smoked)

Units of weekly alcohol consumption

Hours of weekly physical activity

Health indicators

MDI score (0-50)

Physician-diagnosed mental health problem

Number of physician-diagnosed diseases

Psychological treatment $(\geq 1)^{d}$

Stressful life events $(\geq 1)^{d}$

Organizational justice score $(0-10)$

Women

Sociodemographic factors

Age in years

Social class

The salariat

Intermediate occupations

Working class

Cohabiting

Having children living at home

Health-related behavior

BMI (normal weight)

Smoking habits (never smoked)

Units of weekly alcohol consumption

Hours of weekly physical activity

Health indicators

MDI score (0-50)

Physician-diagnosed mental health problem

Number of physician-diagnosed diseases

Psychological treatment $(\geq 1)^{d}$

Stressful life events $(\geq 1)^{\text {d }}$

Organizational justice score (0-10)

\begin{tabular}{|c|c|c|c|c|c|c|c|c|}
\hline \multicolumn{4}{|c|}{ PEWED } & \multicolumn{4}{|c|}{ DANES $a, b$} & \multirow[t]{2}{*}{$P$-value ${ }^{c}$} \\
\hline $\mathrm{N}$ & $\%$ & Mean & SD & $\mathrm{N}$ & $\%$ & Mean & SD & \\
\hline 438 & 42.4 & & & 3329 & 51.5 & & & $<0.0001$ \\
\hline 596 & 57.6 & & & 3134 & 48.5 & & & \\
\hline
\end{tabular}

$\begin{array}{rr}151 & 34.5 \\ 89 & 20.3 \\ 198 & 45.2 \\ 346 & 79.0 \\ 203 & 46.3 \\ & \\ 170 & 38.8 \\ 168 & 38.4\end{array}$

47.8

10.5

1024
783
1436
2728
1406
1341
1462

88

20.1

85

178

19.4

40.6

$\begin{array}{ll}1.4 & 6.3 \\ & 1.2\end{array}$

$\begin{array}{ll}5.2 & 1.8\end{array}$

$47.3 \quad 10.1$

196

31.6
24.1
44.3
82.0
42.3
42.0
44.4

47.8

11.2

0.9479

0.1761

0.1240

0.1074

0.2029

0.0174

$\begin{array}{lll}13.9 & 13.2 & 0.0554\end{array}$

$\begin{array}{lll}6.2 & 4.5 & 0.1501\end{array}$

$4.3 \quad 2.6$

$\begin{array}{lll} & <0.0001\end{array}$

$1.0<-1.1<0.0001$

$\begin{array}{lll}6.2 & 1.8<0.0001\end{array}$

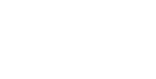

$\begin{array}{ll}195 & 32.7\end{array}$

$206 \quad 34.6$

$455 \quad 76.3$

$260 \quad 43.6$

$284 \quad 47.7$

$250 \quad 42.0$

2.7
2.7
4.6
6.3
3.6

4.7
42.0

1039

1002

1044

2535

1330

33.7

47.6

10.5

0.6146

$1830 \quad 59.5$

$1451 \quad 46.4$

$\begin{array}{rr}9.0 & 10.6 \\ 5.0 & 3.5\end{array}$

(1451

$5.0 \quad 3.5$

$17.4 \quad 7.0$

$\begin{array}{rrrr}150 & 25.2 & 17.4 & 7.0 \\ 170 & 28.5 & 1.3 & 1.2\end{array}$

325

$5.0 \quad 1.9$
32.5

33.8

81.0

42.5

0.8944

0.0094

0.6129

$<0.0001$

0.0446

0.1261

0.0021

$\begin{array}{lll}8.3 & 8.2 & 0.1261 \\ 5.5 & 3.6 & 0.0021\end{array}$

$4.6 \quad 25$

10.4

1.0

$<0.0001$

$<0.0001$

$6.1 \quad 1.8 \quad<0.0001$

a Participants from DANES who (i) were between 18-65 years, (ii) were employed, (iii) responded by mailed/internet questionnaire and with MDI score of $<10$.

${ }^{b}$ Data contains missing values.

c Differences tested with Chi-squared or two sample t-tests.

${ }^{\mathrm{d}}$ Not measured in DANES.

nizational justice had less than half the risk of LTSA. Results were statistically significant for intermediate levels of organizational justice after adjusting for all covariates, including MDI score. For high levels of organizational justice, the RR was statistically significant only in the unadjusted analysis. Among women, neither intermediate nor high levels of organizational justice were statistically significantly associated with risk of LTSA.

Table 3 shows the prospective associations of changes in organizational justice and risk of LTSA. For both men and women, there was no statistically significant effect of either favorable or adverse change in organizational justice on LTSA. 
Table 2. Prospective analyses on exposure to levels of organizational justice and risk of subsequent long-term sickness absence among male $(\mathrm{N}=438)$ and female $(\mathrm{N}=596)$ employees with depressive symptoms at baseline [ $\mathrm{N}=$ number of observations used; Cases=number of LTSA-events; RR=rate ratio; $95 \% \mathrm{Cl}=95 \%$ confidence interval]

\begin{tabular}{|c|c|c|c|c|c|c|c|c|}
\hline \multirow[t]{2}{*}{ Level of organizational justice } & \multirow[t]{2}{*}{$\mathrm{N}$} & \multirow[t]{2}{*}{ Cases } & \multicolumn{2}{|c|}{ Unadjusted } & \multicolumn{2}{|c|}{ Model I a } & \multicolumn{2}{|c|}{ Model II ${ }^{\text {b }}$} \\
\hline & & & $\mathrm{RR}$ & $95 \% \mathrm{Cl}$ & $\mathrm{RR}$ & $95 \% \mathrm{Cl}$ & $\mathrm{RR}$ & $95 \% \mathrm{Cl}$ \\
\hline \multicolumn{9}{|l|}{ Men } \\
\hline Low $^{c}$ & 367 & 30 & 1.00 & & 1.00 & & 1.00 & \\
\hline Intermediate & 510 & 20 & 0.47 & $0.26-0.85^{d}$ & 0.49 & $0.27-0.89 \mathrm{~d}$ & 0.49 & $0.26-0.91^{d}$ \\
\hline High & 563 & 16 & 0.33 & $0.15-0.74$ e & 0.43 & $0.18-1.02$ & 0.47 & $0.20-1.10$ \\
\hline \multicolumn{9}{|l|}{ Women } \\
\hline Low $^{c}$ & 520 & 38 & 1.00 & & 1.00 & & 1.00 & \\
\hline Intermediate & 743 & 68 & 1.25 & $0.76-2.05$ & 1.24 & $0.77-2.01$ & 1.29 & $0.81-2.06$ \\
\hline High & 744 & 57 & 1.03 & $0.60-1.78$ & 0.90 & $0.52-1.56$ & 0.95 & $0.55-1.62$ \\
\hline
\end{tabular}

a Adjusted for age, social class, body mass index, smoking habits, pre-existing physician-diagnosed mental health problem, pre-existing physiciandiagnosed diseases, psychological treatment, and stressful life events.

${ }^{\mathrm{b}}$ Adjusted for covariates from Model I plus Major Depression Inventory (MDI) score.

${ }^{c}$ The average level of organizational justice divided into three groups: low levels are the reference.

d $P<0.05$.

${ }^{e} \mathrm{P}<0.01$.

Table 3. Prospective analyses on changes in organizational justice and risk of subsequent long-term sickness absence (LTSA) among male $(\mathrm{N}=438)$ and female $(\mathrm{N}=596)$ employees with depressive symptoms at baseline. [N=number of observations used; cases=number of LTSA events; $\mathrm{RR}=$ rate ratio; $95 \% \mathrm{Cl}=95 \%$ confidence interval]

\begin{tabular}{|c|c|c|c|c|c|c|c|c|c|c|}
\hline \multirow[t]{2}{*}{ Type of change } & \multirow[t]{2}{*}{$\mathrm{N}$} & \multirow[t]{2}{*}{ Cases } & \multicolumn{2}{|c|}{ Unadjusted } & \multicolumn{2}{|c|}{ Model I a } & \multicolumn{2}{|c|}{ Model II b } & \multicolumn{2}{|c|}{ Model III c } \\
\hline & & & $\mathrm{RR}$ & $95 \% \mathrm{Cl}$ & $\mathrm{RR}$ & $95 \% \mathrm{Cl}$ & $\mathrm{RR}$ & $95 \% \mathrm{Cl}$ & $\mathrm{RR}$ & $95 \% \mathrm{Cl}$ \\
\hline \multicolumn{11}{|l|}{ Men } \\
\hline Favourable & 265 & 13 & 1.23 & $0.61-2.49$ & 1.00 & $0.50-2.02$ & 0.97 & $0.47-2.00$ & 0.90 & $0.45-1.80$ \\
\hline None $^{d}$ & 1006 & 41 & 1.00 & & 1.00 & & 1.00 & & 1.00 & \\
\hline Adverse & 169 & 12 & 1.82 & $0.86-3.85$ & 1.63 & $0.75-3.53$ & 1.77 & $0.81-3.86$ & 2.00 & $0.86-4.64$ \\
\hline \multicolumn{11}{|l|}{ Women } \\
\hline Favourable & 364 & 28 & 0.91 & $0.62-1.34$ & 0.88 & $0.59-1.31$ & 0.82 & $0.55-1.24$ & 0.79 & $0.52-1.20$ \\
\hline None ${ }^{d}$ & 1420 & 118 & 1.00 & & 1.00 & & 1.00 & & 1.00 & \\
\hline Adverse & 223 & 17 & 0.92 & $0.57-1.48$ & 0.88 & $0.53-1.45$ & 0.88 & $0.52-1.46$ & 0.88 & $0.53-1.48$ \\
\hline
\end{tabular}

${ }^{a}$ Adjusted for age, social class, body mass index, smoking habits, pre-existing physician-diagnosed mental health problem, pre-existing physiciandiagnosed diseases, psychological treatment, stressful life events.

${ }^{b}$ Adjusted for covariates from Model I plus Major Depression Inventory (MDI) score.

${ }^{c}$ Adjusted for covariates from model II plus initial level of organizational justice.

${ }^{d}$ Changes in the level of organizational justice. No changes are the reference.

\section{Sensitivity analysis}

When we excluded participants with LTSA one year before baseline from the analyses, effects of levels of organizational justice and risk of subsequent LTSA were similar to the main analyses. For the analyses of changes in organizational justice, the effect of adverse changes for men became stronger and statistically significant, however with wide confidence limits. Analyses restricted to first occurrence of LTSA attenuated the risk estimates, and the risk estimate for intermediate levels organizational justice for men was no longer statistically significant. Finally, results remained unchanged when working hours were included as a covariate. Detailed results of these analyses are available on request from the first author.

\section{Discussion}

Our hypotheses that high levels of organizational justice and the improvement thereof would be associated with a decreased risk of LTSA among employees with depressive symptoms were only partly confirmed. Among men, we found that intermediate levels of organizational justice statistically significantly predicted decreased risk of subsequent LTSA. There was also a tendency towards a decreased risk for men with high organizational justice, although not statistically significant in the adjusted models. Among women, organizational justice was not related to LTSA. In both sexes, changes in organizational justice did not predict risk of LTSA.

Findings on sex differences from previous studies of organizational justice and morbidity are inconsistent. 
Some studies have reported no difference for men and women $(15,19,20)$, whereas other studies have found distinct differences and suggested that possible explanations for the differences might include differences in occupational positions, social roles, expectations of supervisors (37), and relational orientation (38). Some studies $(17,39$, 40) have reported no statistically significant sex interaction with organizational justice, but still there are indications of differences. Head et al (17) found that relational justice, a component of organizational justice pertaining to a considerate, fair and respectful treatment from supervisors $(15,16)$, predicted sickness absence and that this association appeared to be stronger among women than men. In contrast, two other studies found relational justice to predict poor self-rated health (39) and psychiatric morbidity (40) more strongly among men than women (40). These earlier studies were all conducted in samples that did not examine the level of depressive symptoms among the employees, whereas the present study examined a sample of employees with depressive symptoms.

Mental health problems may affect men and women differently. For example, a study by Angst et al (41) found that men more frequently attributed the onset of their depression to problems at work, whereas women attributed onset of depression to relationship problems and illness or death in the family. Furthermore, depressed men experienced impairment in workability more adversely than depressed women. In another study, Stansfeld et al (42) found greater effect estimates of mental health problems with regard to sickness absence among men than women. When the analyses were adjusted for work and non-work social support and other non-work factors, the effects were no longer statistically significant for women.

Women with depressive symptoms have been found to seek treatment more often than men with depressive symptoms (41). In our study, $19.4 \%$ of men and $28.5 \%$ of women used some kind of psychological treatment. That men seek help less often than women when experiencing mental health problems might render them more vulnerable to influences from their environment, including the work environment. Thus, men may benefit more from protective working conditions than women. Furthermore, the importance of organizational justice for men may reflect the importance of the work role for men's mental health, as suggested by Plaisier et al (43) who found that paid employment was strongly associated with a reduced prevalence of depression and anxiety among men but not women.

Finally, in Denmark, the labor market is strongly sex-segregated, with women more likely to work in the public sector and men more likely to work in the private sector (44). Work values might differ for employees in the public versus the private sector and thus affect the importance of organizational justice differently.
Two previous studies have reported that favorable changes in relational justice predicted lower risk of poor self-rated health (39) and minor psychiatric morbidity (40). To the best of our knowledge no previous studies have examined the effect of changes in organizational justice on sickness absence. In our study, changes in organizational justice were not statistically significantly associated with LTSA. Several explanations for the lack of association are possible. First, the majority of employees in our study did not experience changes in organizational justice, and the changes that occurred might have been too small to create sufficient exposure contrast to generate an effect. Second, sometimes positive changes in organizational justice might be accompanied with negative changes in other areas at work, and vice versa, which may offset any effects on LTSA. For example, the replacement of a problematic supervisor might lead to an increase in organizational justice, however, the effect on health and subsequent LTSA might be offset by heightened insecurity, lower role clarity, and lower predictability during the replacement process. Third, the potential effects of change in organizational justice might be delayed and therefore not captured within four months of follow-up.

As delineated in the introduction, we are not aware of other studies that have examined the association of organizational justice on LTSA among employees with mental health problems. A few studies have taken related approaches to examine the interplay between work environment and vulnerability on risk of sickness absence. Väänänen et al (45) found that high social support at work decreased the negative effect of psychological symptoms on sickness absence among male but not female employees. Virtanen et al (8) found no statistically significant interaction between job strain and psychological distress in predicting LTSA in a predominantly female population. Munir et al (46) reported that quality of leadership was more strongly associated with risk of LTSA among employees with depressive symptoms, however, the interaction was not statistically significant. Finally, Elovainio et al (47) found that the association of vulnerability, defined as exposure to a stressful life event, with risk of LTSA was weaker in work units with high levels of organizational justice. In sum, although the findings from these studies are not consistent, they generally appear to be in line with our finding that good psychosocial working conditions might buffer the effect of mental health problems on LTSA, and that effects might be different for men and women.

\section{Strengths and weaknesses of the study}

The repeated exposure measurements are a strong feature of this study as averages of repeated measurements are more stable and reliable than single measurements 
of working conditions (48). We used a national register to assess LTSA as register data on sickness absence are considered more reliable than self-reported data (27). The register-based outcome measure also ensured that results were not biased due to common method variance (49) and almost all participants could be followed-up. Furthermore, we adjusted for time-invariant and timevarying covariates known for their association with both sickness absence and mental health problems.

Of the 2271 invited DANES respondents, 65\% agreed to participate and response rates during followup ranged from $86-91 \%$. Given the vulnerable study population, we consider these response rates as very satisfactory. The non-response analysis revealed no selection in relation to exposure and outcome.

Several limitations of the study must be considered. First, we were restricted to measure organizational justice with only two items, derived from the four-item justice scale of the COPSOQ II (26). Other prospective studies have used more comprehensive measures of organizational justice, often the scales originally developed by Moorman (50) and modified by Elovainio et al (15) and Kivimäki et al (19). These scales distinguish between distributive, procedural, and relational justice. We cannot rule out that a more comprehensive measure of organizational justice, and a distinction between different organizational justice components, might have yielded different results.

Second, we measured both organizational justice and depressive symptoms self-reportedly, which involves the risk of reporting bias (51) that may artificially inflate associations between exposure and outcome. Although reporting bias is an important concern, we consider this issue less problematic in the present study as all of our participants had some degree of depressive symptoms. Consequently, the selection of participants likely reduced the magnitude of any reporting bias. Moreover, we assessed depressive symptoms in all waves of data collection, and our results were robust to adjustment for the time-varying MDI score.

Third, some covariates (eg, BMI and smoking habits) were only assessed at baseline because we wanted to keep the follow-up questionnaire brief to lower the burden on respondents and ensure a high response rate. Consequently, these covariates could only be analyzed as time-invariant covariates, even though some of them might have changed during follow-up.

Fourth, the study sample and number of events were relatively small for an epidemiological study on LTSA. This did not allow us to conduct further sensitivity analyses. For example, we could not conduct stratified analyses to examine whether changes from low to intermediate organizational justice scores had different effects than changes from intermediate to high organizational justice scores.
Fifth, the relation of depressive symptoms, organizational justice and LTSA is complex. We used organizational justice as a predictor variable and LTSA as the outcome in a cohort of employees who at baseline had depressive symptoms. However, other pathways are also possible. Findings from a recent review indicate that exposure to low organizational justice may be an important risk factor in the etiology of mental health problems (16). We do not know the causes of depressive symptoms at baseline and thus we cannot preclude that organizational justice before baseline (T0) could have played a role in the etiology of the depressive symptoms at baseline.

Finally, we intentionally sampled the PEWED study population from a sample of the Danish population (DANES) to represent a subgroup of employees at high risk of LTSA. Consequently, the findings cannot be generalized to general working populations, however, the findings may be generalizable to employees with depressive symptoms.

\section{Concluding remarks}

In summary, we found that organizational justice is associated with a decreased risk of LTSA among men, but not women, with depressive symptoms. Thus, improving organizational justice in organizations might be a venue for reducing LTSA among employees with mental health problems at least for male employees. Further studies with more comprehensive measurements of organizational justice are needed to corroborate the findings. These studies should also further examine sex differences in association between organizational justice and LTSA among employees with depressive symptoms and other mental health problems.

\section{Acknowledgments}

The Danish Working Environment Research Fund supported this study (grant number: 03-2008-09). The funding source had no role in the study's design, data collection, analysis, interpretation of data, or the decision to submit the paper for publication.

The authors declare no conflict of interest.

\section{References}

1. Lund T, Kivimäki M, Labriola M, Villadsen E, Christensen KB. Using administrative sickness absence data as a marker of future disability pension: the prospective DREAM study of Danish private sector employees. Occup Environ Med. 2008;65:28-31. http://dx.doi.org/10.1136/oem.2006.031393. 
2. Kivimäki M, Head J, Ferrie JE, Shipley MJ, Vahtera J, Marmot MG. Sickness absence as a global measure of health: evidence from mortality in the Whitehall II prospective cohort study. Br Med J. 2003;327:364-8. http://dx.doi.org/10.1136/ bmj.327.7411.364.

3. Vahtera J, Pentti J, Kivimäki M. Sickness absence as a predictor of mortality among male and female employees. J Epidemiol Community Health. 2004;58:321-6. http://dx.doi. org/10.1136/jech.2003.011817.

4. Alonso J, Angermeyer MC, Bernert S, Bruffaerts R, Brugha TS, Bryson H, et al. Disability and quality of life impact of mental disorders in Europe: results from the European Study of the Epidemiology of Mental Disorders (ESEMeD) project. Acta Psychiatr Scand. 2004;109 (Suppl. 420):38-46. http:// dx.doi.org/10.1111/j.1600-0047.2004.00325.x.

5. Lerner D, Henke RM. What does research tell us about depression, job performance, and work productivity? J Occup Environ Med. 2008;50:401-10. http://dx.doi.org/10.1097/ JOM.0b013e31816bae50.

6. Bültmann U, Rugulies R, Lund T, Christensen KB, Labriola $\mathrm{M}$, Burr H. Depressive symptoms and the risk of long-term sickness absence: a prospective study among 4747 employees in Denmark. Soc Psychiatry Psychiatr Epidemiol. 2006;41:87580. http://dx.doi.org/10.1007/s00127-006-0110-y.

7. Lexis MAS, Jansen NWH, van Amelsvoort LGPM, van den Brandt PA, Kant I. Depressive Complaints as a Predictor of Sickness Absence Among the Working Population. J Occup Environ Med. 2009;51:887-95. http://dx.doi.org/10.1097/ JOM.0b013e3181aa012a.

8. Virtanen M, Vahtera J, Pentti J, Honkonen T, Elovainio M, Kivimäki M. Job strain and psychologic distress influence on sickness absence among Finnish employees. Am J Prev Med. 2007;33:182-7. http://dx.doi.org/10.1016/j. amepre.2007.05.003.

9. Hjarsbech PU, Andersen RV, Christensen KB, Aust B, Borg V, Rugulies R. Clinical and non-clinical depressive symptoms and risk of long-term sickness absence among female employees in the Danish eldercare sector. J Affect Disord. 2011;129:87-93. http://dx.doi.org/10.1016/j.jad.2010.07.033.

10. OECD. Sick on the Job? Myths and Realities about Mental Health and Work. Paris: OECD Publishing; 2012.

11. Bültmann U, Christensen KB, Burr H, Lund T, Rugulies R. Severe depressive symptoms as predictor of disability pension: a 10-year follow-up study in Denmark. Eur J Public Health. 2008;18:232-4. http://dx.doi.org/10.1093/eurpub/ckm132.

12. OECD. Mental Health and Work. Paris: OECD Publishing; 2013.

13. World Health Organization (WHO). International classification of functioning, disability and health (ICF). Geneva: WHO; 2001.

14. Alexanderson K, Norlund A. Swedish Council on Technology Assessment in Health Care (SBU). Chapter 1. Aim, background, key concepts, regulations, and current statistics. Scand J Public Health Suppl. 2004;63:12-30. http://dx.doi. org/10.1080/14034950410021808.
15. Elovainio M, Kivimäki M, Vahtera J. Organizational justice: evidence of a new psychosocial predictor of health. Am J Public Health. 2002;92:105-8. http://dx.doi.org/10.2105/ AJPH.92.1.105.

16. Ndjaboue R, Brisson C, Vezina M. Organizational justice and mental health: a systematic review of prospective studies. Occup Environ Med. 2012;69:694-700. http://dx.doi. org/10.1136/oemed-2011-100595.

17. Head J, Kivimaki M, Siegrist J, Ferrie JE, Vahtera J, Shipley MJ, et al. Effort-reward imbalance and relational injustice at work predict sickness absence: the Whitehall II study. J Psychosom Res. 2007;63:433-40. http://dx.doi.org/10.1016/j. jpsychores.2007.06.021.

18. Elovainio M, Kivimäki M, Steen N, Vahtera J. Job decision latitude, organizational justice and health: multilevel covariance structure analysis. Soc Sci Med. 2004;58:1659-69. http://dx.doi.org/10.1016/S0277-9536(03)00366-6.

19. Kivimäki M, Elovainio M, Vahtera J, Ferrie JE. Organizational justice and health of employees: prospective cohort study. Occup Environ Med. 2003;60:27-33. http://dx.doi. org/10.1136/oem.60.1.27

20. Ybema JF, van den Bos K. Effects of organizational justice on depressive symptoms and sickness absence: a longitudinal perspective. Soc Sci Med. 2010;70:1609-17. http://dx.doi. org/10.1016/j.socscimed.2010.01.027.

21. Sønderstrup-Andersen HHK, Carlsen K, Kines P, Bjørner JB, Roepstorff C. Exploring the relationship between leadership style and safety climate in a large scale danish cross-sectional study. Safety Science Monitor. 2011;15:Article 8.

22. Thorsen S, Rugulies R, Longaard K, Borg V, Thielen K, Bjorner JB. The association between psychosocial work environment, attitudes towards older workers (ageism) and planned retirement. Int Arch Occup Environ Health. 2012;85:437-45. http://dx.doi.org/10.1007/s00420-011-0689-5.

23. Feveile H, Olsen O, Hogh A. A randomized trial of mailed questionnaires versus telephone interviews: response patterns in a survey. BMC Med Res Methodol. 2007;7:27. http:// dx.doi.org/10.1186/1471-2288-7-27.

24. Bech P, Rasmussen NA, Olsen LR, Noerholm V, Abildgaard W. The sensitivity and specificity of the Major Depression Inventory, using the Present State Examination as the index of diagnostic validity. J Affect Disord. 2001;66:159-64. http:// dx.doi.org/10.1016/S0165-0327(00)00309-8.

25. Olsen LR, Jensen DV, Noerholm V, Martiny K, Bech P. The internal and external validity of the Major Depression Inventory in measuring severity of depressive states. Psychol Med. 2003;33:351-6. http://dx.doi.org/10.1017/ S0033291702006724.

26. Pejtersen JH, Kristensen TS, Borg V, Bjorner JB. The second version of the Copenhagen Psychosocial Questionnaire. Scand J Public Health. 2010;38:8-24. http://dx.doi. org/10.1177/1403494809349858.

27. Hjollund NH, Larsen FB, Andersen JH. Register-based followup of social benefits and other transfer payments: Accuracy and degree of completeness in a Danish interdepartmental administrative database compared with a population-based 
survey. Scand J Public Health. 2007;35:497-502. http:// dx.doi.org/10.1080/14034940701271882.

28. Thielen K, Nygaard E, Andersen I, Diderichsen F. Employment consequences of depressive symptoms and work demands individually and combined. Eur J Public Health. 2013 Feb 1. [Epub ahead of print] http://dx.doi.org/10.1093/eurpub/ckt011.

29. Rose D, Harrison E. The European Socio-economic Classification: A New Class Schema for Comparative European Research. European Societies. 2007;9:459-90. http://dx.doi.org/10.1080/14616690701336518.

30. Mastekaasa A. Parenthood, gender and sickness absence. Soc Sci Med. 2000;50:1827-42. http://dx.doi.org/10.1016/ S0277-9536(99)00420-7.

31. Christensen KB, Lund T, Labriola M, Bültmann U, Villadsen E. The impact of health behaviour on long term sickness absence: Results from DWECS/DREAM. Ind Health. 2007;45:348-51. http://dx.doi.org/10.2486/indhealth.45.348.

32. Lund T, Labriola M, Villadsen E. Who is at risk for longterm sickness absence? A prospective cohort study of Danish employees. Work. 2007;28:225-30.

33. Duijts SFA, Kant J, Swaen GMH, van den Brandt PA, Zeegers MPA. A meta-analysis of observational studies identifies predictors of sickness absence. J Clin Epidemiol. 2007;60:1105-15. http://dx.doi.org/10.1016/j. jclinepi.2007.04.008.

34. Kessing LV, Agerbo E, Mortensen PB. Does the impact of major stressful life events on the risk of developing depression change throughout life? Psychol Med. 2003;33:1177-84. http://dx.doi.org/10.1017/S0033291703007852.

35. Christensen KB, Lund T, Labriola M, Villadsen E, Bültmann $\mathrm{U}$. The fraction of long-term sickness absence attributable to work environmental factors: prospective results from the Danish Work Environment Cohort Study. Occup Environ Med. 2007;64:487-9. http://dx.doi.org/10.1136/oem.2006.028563.

36. Lund T, Labriola M, Christensen KB, Bültmann U, Villadsen E, Burr H. Psychosocial work environment exposures as risk factors for long-term sickness absence among Danish employees: Results from DWECS/DREAM. J Occup Environ Med. 2005;47:1141-7. http://dx.doi.org/10.1097/01. jom.0000174301.80318.f2.

37. Sutinen R, Kivimäki M, Elovainio M, Virtanen M. Organizational fairness and psychological distress in hospital physicians. Scand J Public Health. 2002;30:209-15. http:// dx.doi.org/10.1080/14034940210133843.

38. Inoue A, Kawakami N, Tsuno K, Tomioka K, Nakanishi M. Organizational Justice and Psychological Distress Among Permanent and Non-permanent Employees in Japan: A Prospective Cohort Study. Int J Behav Med. 2013 Jun;20(2):26576. http://dx.doi.org/10.1007/s12529-012-9224-7.

39. Kivimäki M, Ferrie JE, Head J, Shipley MJ, Vahtera J, Marmot MG. Organizational justice and change in justice as predictors of employee health: the Whitehall II study. J Epidemiol Community Health. 2004;58:931-7. http://dx.doi. org/10.1136/jech.2003.019026.

40. Ferrie JE, Head J, Shipley MJ, Vahtera J, Marmot MG, Kivimäki
M. Injustice at work and incidence of psychiatric morbidity: the Whitehall II study. Occup Environ Med. 2006;63:443-50. http://dx.doi.org/10.1136/oem.2005.022269.

41. Angst J, Gamma A, Gastpar M, Lepine JP, Mendlewicz J, Tylee A. Gender differences in depression. Epidemiological findings from the European DEPRES I and II studies. Eur Arch Psychiatry Clin Neurosci. 2002;252:201-9. http://dx.doi. org/10.1007/s00406-002-0381-6.

42. Stansfeld SA, Fuhrer R, Head J. Impact of common mental disorders on sickness absence in an occupational cohort study. Occup Environ Med. 2011;68:408-13. http://dx.doi. org/10.1136/oem.2010.056994.

43. Plaisier I, de Bruijn JG, Smit JH, de Graaf, Ten Have M, Beekman AT, et al. Work and family roles and the association with depressive and anxiety disorders: differences between men and women. J Affect Disord. 2008;105:63-72. http:// dx.doi.org/10.1016/j.jad.2007.04.010.

44. Estevez-Abe M. Gender bias in skills and social policies: The varieties of capitalism perspective on sex segregation. Social Politics. 2005;12:180-215. http://dx.doi.org/10.1093/sp/jxi011.

45. Väänänen A, Toppinen-Tanner S, Kalimo R, Mutanen P, Vahtera J, Peiro JM. Job characteristics, physical and psychological symptoms, and social support as antecedents of sickness absence among men and women in the private industrial sector. Soc Sci Med. 2003;57:807-24. http://dx.doi. org/10.1016/S0277-9536(02)00450-1.

46. Munir F, Burr H, Hansen JV, Rugulies R, Nielsen K. Do positive psychosocial work factors protect against 2-year incidence of long-term sickness absence among employees with and those without depressive symptoms? A prospective study. J Psychosom Res. 2011;70:3-9. http://dx.doi.org/10.1016/j. jpsychores.2010.09.014.

47. Elovainio M, Kivimaki M, Linna A, Brockner J, van den BK, Greenberg J, et al. Does organizational justice protect from sickness absence following a major life event? A Finnish public sector study. J Epidemiol Community Health. 2010;64:470-2. http://dx.doi.org/10.1136/jech.2008.084301.

48. Taris TW, Kompier M. Challenges in longitudinal designs in occupational health psychology. Scand J Work Environ Health. 2003;29(1):1-4. http://dx.doi.org/10.5271/sjweh.697.

49. Podsakoff PM, MacKenzie SB, Lee JY, Podsakoff NP. Common method biases in behavioral research: A critical review of the literature and recommended remedies. J Appl Psychol. 2003;88:879-903. http://dx.doi.org/10.1037/00219010.88.5.879.

50. Moorman R. Relationship between organizational justice and organizational citizenship behaviors: do fairness perceptions influence employee citizenship? J Appl Psychol. 1991;76:84555. http://dx.doi.org/10.1037/0021-9010.76.6.845.

51. Frese M, Zapf D. Methodological issues in the study of work stress: Objective vs subjective measurement of work stress and the question of longitudinal studies. In: Cooper CL, Payne R, editors. Causes, coping and consequences of stress at work. Chichester, England: John Wiley \& Sons Ltd; 1988. p. 375-411.

Received for publication: 11 March 2013 